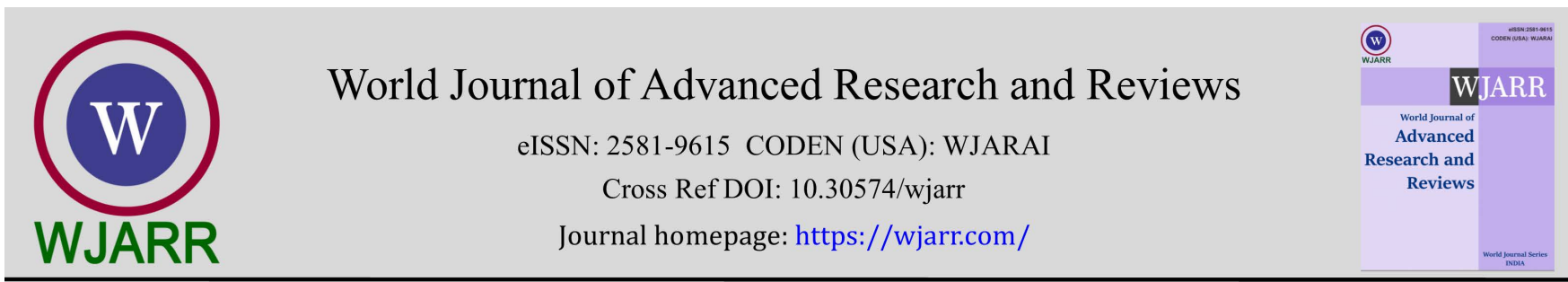

(RESEARCH ARTiClE)

\title{
Prevalence of Toxoplasmosis antibodies in blood donors in Tripoli area
}

\author{
Khaled A. Alawaini 1, ${ }^{*}$, Safia O. Albhlool ${ }^{2}$, Entesar O. Shaife ${ }^{2}$, Hanein A. Qreiwa ${ }^{2}$ and Manal K. Abodena ${ }^{2}$ \\ ${ }^{1}$ Biochemistry department, Memorial University, Canada. \\ ${ }^{2}$ Higher institute of science and medical technology, Jado, Libya.
}

World Journal of Advanced Research and Reviews, 2021, 10(02), 169-175

Publication history: Received on 07 April 2021; revised on 12 May 2021; accepted on 15 May 2021

Article DOI: https://doi.org/10.30574/wjarr.2021.10.2.0219

\begin{abstract}
Toxoplasma gondii is the organism that is responsible for toxoplasmosis disease. Toxoplasma gondii: is a crucial obligate intracellular parasite of humans and animals worldwide and infects nearly one-third of humanity; the disease can be severe and can lead to abortion or neonate's death. In addition, an immunocompromised individual may develop several syndromes such as encephalitis, chorioretinitis, congenital infection and neonatal mortality. In this study, our objective is to determine the prevalence of Toxoplasma gondii antibodies through blood transfusion. Therefore, our study was conducted from 1 May 2010 to 31 of May 2010 among Libyan donors. We tested 164 blood donors from different ages for Toxoplasma gondii antibodies in Tripoli, a capital city of Libya. The results showed that 33.5\% of blood donors had positive IgG antibodies. Therefore, this study suggest blood screening with high-performance techniques for Toxoplasma gondii before blood transfusion should be routinely done to avoid severe complications.
\end{abstract}

Keywords: Toxoplasma gondii; Donor; Tripoli

\section{Introduction}

Toxoplasmosis is a zoonotic disease caused by an intracellular parasite called Toxoplasma gondii (1), which was first reported in 1908 by Nicolle and Manceaux in a North African rodent, gundi (Ctenodactylus gundi), in Tunisia (2). The parasite has two steps life cycle. In the cat, the sexual stage took place. However, the asexual stage appears in mammals and birds $(3,14)$. A study estimated that a third of the world's human population is exposed to the infection with Toxoplasma (4). Several animals as well can be infected. As a result, the human can be infected and considered the intermediate host of the obligate intracellular parasite (T. gondii). However, cats are the definitive host to Toxoplasma gondii, and counted as the primary human infection source (1). The primary infection is mostly asymptomatic in pregnant women (5) and can cause abortion to pregnant women or animals (6).

The parasite can cross the placenta, infect the fetus, and cause mental retardation or other complication, eventually leading to fetal death. (5). Moreover, Toxoplasmosis is opportunistic and can cause severe complications to immunocompromised individuals (1). Toxoplasma gondii is usually transmitted by ingesting contaminated food with oocysts or eating raw meat (6) and from mother to child through the placenta (7) it has been estimated that $30 \%$ are at high risk of infection during the third trimester of pregnancy (8). However, it is also transmitted through blood transfusion (7) or organ transplantation (7). Blood donors who had an acute infection can transmit the disease to the receipt individuals (7). Rad et al. 2016 mentioned that out of 20,964 blood donors were screened for Toxoplasma antibodies during the period from 1980 to 2015, so they found that the seropositivity of antibodies was 33\% (9). However, the highest and lowest of toxoplasma antibodies were found in Africa and Asia. For example, in Ethiopia, 73\% had the highest percentage of seropositive results; in contrast, Namibia had the lowest prevalence, 1\% was found (9).

\footnotetext{
* Corresponding author: Khaled A. Alawaini

Biochemistry department, Memorial University, Canada.
} 
Due to the simple transmission route, as described either through contaminated food or uncooked meat, we expected availability of Toxoplasma gondii antibodies in blood donors could lead to many undesirable complications.

\section{Objective}

To determine the prevalence of Toxoplasma gondii antibodies among Libyan blood donors who attended Tripoli health centers.

\section{Methods}

This study was conducted in the endemic disease center in Tripoli. Samples were collected from three different health centers area (El Zawia street hospital, Al Jalaa hospital, and Abu Salim hospital). A total of 164 randomly collected donors' blood of different ages ranged from 18-52 years old with a mean age of 35 years. However, the venous blood samples were collected in a container free from anticoagulants. Samples were centrifuged at 3000 for 10 minutes, and serum was separated and stored at -20 until further analysis. Our data revealed that most blood donors were in the age group from 25 to 31 years. The study was conducted from 1 May 2010 to 31 May 2010 among Libyan donors. All donor individuals were given a questionnaire before blood collection, which sought information for each donor about a name, age, sex, occupation, residence, in addition to surgical history, blood transfusion, food habits, and animal contact. Out of the 164 subjects who were approached to participate in the study, all donors (100\%) provided full information included. Rapid toxoplasmosis biokit reagent (Toxocell Latex) was used in this study to search for the presence of toxoplasma antibodies.

\subsection{Components}

Latex reagent, suspension of polystyrene latex particles coated with Toxoplasma gondii soluble antigen in a buffer containing bovine serum albumen.

\subsection{Positive control}

Diluted human serum containing rabbit IgG anti Toxoplasma. When the latex reagent is mixed with the serum, if the serum contains approximately more than $10 \mathrm{lu} / \mathrm{ml}$ of toxoplasma antibodies, a clear agglutination zone will appear.

\subsection{Negative control}

Non-reactive diluted human serum.

\subsection{Procedure technique}

On a specific slide drop of $50 \mathrm{ul}$ of the serum was placed on one section of the side as well as one drop of control onto the other section of the slide. A drop of latex was mixed with the sample. Then the slide was placed on shaker for 5 minutes. Data were analyzed with computer software SPSS (Statistical Package for Social Science), version 15. SPSS Inc., Chicago, IL).

\section{Results}

Overall, 164 blood donors participated in the current study with a mean age of 35 . All donors were males, and the majority (41.5\%) were in the age group between 25-31. Most donors (76 or $46.3 \%$ ) were unemployed or farmer. As a result, Seroprevalence of Anti-T. gondii antibodies were found $17.1 \%$ in individuals who were unemployed or farmer. However, in general, antibodies were found in the serum of 55 out of all blood donors. Of these, 55 cases, only 7 donors received a blood transfusion in past, and 3 people tested seropositive for T. gondii antibodies. Seropositivity in 15 individuals with animal contact was $46.66 \%$ versus $53.33 \%$ seronegative; this positive seropositivity represented $4.3 \%$ of all blood donors in different sociodemographic.

Data represented donated individuals from different areas in Tripoli city. The majority were from Abu Salim Hospital and $\mathrm{Al}$ Jalaa Hospital. There was a significant effect $(P<0.05)$ between seropositivity and collection places, which might be affected by different sample numbers in different places.

Occupation showed high prevalence of Toxoplasma gondii in unemployed compared with the other jobs. Although the sample size in this group was highest which reflected high infected group but also, we might consider this group was less educated than other groups. 
Table 1 The distribution of donors, depending on the source of blood samples.

\begin{tabular}{|l|l|l|l|l|}
\hline \multirow{2}{*}{ Health care Centre } & \multicolumn{2}{|l|}{ Results } & \multirow{2}{*}{ Total } \\
\cline { 3 - 5 } \multicolumn{2}{|l|}{ Abu Salim } & Seropositive & Seronegative & \\
\hline \multirow{3}{*}{ Aljalaa } & Count & 20 & 62 & 82 \\
\cline { 2 - 5 } & \% of Total & 12.2 & 37.8 & $50.0 \%$ \\
\hline \multirow{3}{*}{ El Zawia street } & Count & 31 & 41 & 72 \\
\cline { 2 - 5 } & \% of Total & 18.9 & 25.0 & $43.9 \%$ \\
\hline \multirow{3}{*}{ Total } & Count & 4 & 6 & 10 \\
\cline { 2 - 5 } & \% of Total & 2.4 & 3.6 & $6.1 \%$ \\
\hline & Count & 55 & 109 & 164 \\
\cline { 2 - 5 } & \% of Total & $33.4 \%$ & 66.4 & 100.0 \\
\hline
\end{tabular}

Data represented donor individuals from different areas in Tripoli city. The majority were from Abu Salim Hospital and Aljalaa Hospital. There was a significant effect $(P<0.05)$ between seropositivity and collection places, which might be affected by different sample numbers in different places.

Table 2 The distribution of age grouping of the population in blood donors.

\begin{tabular}{|c|c|c|c|c|}
\hline \multicolumn{2}{|c|}{ Donor age } & \multicolumn{2}{|l|}{ Results } & \multirow{3}{*}{\begin{tabular}{|l} 
Total \\
37
\end{tabular}} \\
\hline & & \multirow{2}{*}{$\begin{array}{l}\text { Seropositive } \\
17\end{array}$} & \multirow{2}{*}{$\begin{array}{l}\text { Seronegative } \\
20\end{array}$} & \\
\hline $18-24$ & Count & & & \\
\hline & $\%$ of Total & 10.4 & 12.2 & 22.6 \\
\hline \multirow[t]{2}{*}{$25-31$} & Count & 20 & 48 & 68 \\
\hline & $\%$ of Total & 12.2 & 29.3 & 41.5 \\
\hline \multirow[t]{2}{*}{$32-38$} & Count & 14 & 26 & 40 \\
\hline & $\%$ of Total & 8.5 & 15.9 & 24.4 \\
\hline \multirow[t]{2}{*}{$39-45$} & Count & 4 & 12 & 16 \\
\hline & $\%$ of Total & 2.4 & 7.3 & ح9.8 \\
\hline \multirow[t]{2}{*}{$46-52$} & Count & 0 & 3 & 3 \\
\hline & $\%$ of Total & 0 & 1.8 & 1.8 \\
\hline \multirow[t]{2}{*}{ Total } & Count & 55 & 109 & 164 \\
\hline & $\%$ of Total & 33.5 & 66.5 & 100.0 \\
\hline
\end{tabular}

Higher prevalence of Toxoplasma gondii in the age group 25-31 years old when compared to the age group between 3945 old. In general, $33.5 \%$ tested positive whereas the remaining $66.5 \%$ were negative. 
Table 3 The relation between seropositivity and donor's occupation.

\begin{tabular}{|c|c|c|c|c|}
\hline \multicolumn{2}{|l|}{ Occupation } & \multicolumn{2}{|l|}{ Result } & \multirow{3}{*}{$\begin{array}{l}\text { Total } \\
2 \\
\end{array}$} \\
\hline & & \multirow{2}{*}{$\begin{array}{l}\text { Seropositive } \\
0 \\
\end{array}$} & \multirow{2}{*}{$\begin{array}{l}\text { Seronegative } \\
2 \\
\end{array}$} & \\
\hline Engineer & Count & & & \\
\hline & $\%$ of Total & 0 & 1.2 & 1.2 \\
\hline \multirow[t]{2}{*}{ Unemployed } & Count & 28 & 48 & 76 \\
\hline & $\%$ of Total & 17.1 & 29.3 & 46.4 \\
\hline \multirow[t]{2}{*}{ Military } & Count & 5 & 6 & 11 \\
\hline & $\%$ of Total & 3.0 & 3.7 & 6.7 \\
\hline \multirow[t]{2}{*}{ Employee } & Count & 18 & 49 & 67 \\
\hline & $\%$ of Total & 11.0 & 29.9 & 40.9 \\
\hline \multirow[t]{2}{*}{ Students } & Count & 4 & 4 & 8 \\
\hline & $\%$ of Total & 2.4 & 2.4 & $\sim 4.9$ \\
\hline \multirow[t]{2}{*}{ Total } & Count & 55 & 109 & 164 \\
\hline & $\%$ of Total & 33.5 & 66.5 & 100.0 \\
\hline
\end{tabular}

Occupation showed high prevalence of Toxoplasma gondii in unemployed compared with other jobs. Although the sample size in this group was highest which reflected high infected group but also, we might consider this group was less educated than other groups.

Table 4 The distribution of individual depends on animal contact.

\begin{tabular}{|l|l|l|l|l|}
\hline \multicolumn{2}{|l|}{ Animal contact } & Results & \multirow{2}{*}{ Total } \\
\cline { 3 - 4 } \multicolumn{2}{|l|}{ Yes } & Seropositive & Seronegative & \\
\cline { 2 - 5 } & Count & 7 & 8 & 15 \\
\hline \multirow{2}{*}{ No } & Count Total & 4.3 & 4.9 & $\sim 9.1 \%$ \\
\cline { 2 - 5 } & $\%$ of Total & 48 & 101 & 149 \\
\hline \multirow{2}{*}{ Total } & Count & 55.3 & 61.6 & $90.9 \%$ \\
\cline { 2 - 5 } & $\%$ of Total & $33.5 \%$ & 66.5 & 164 \\
\hline
\end{tabular}

Out of 164 blood donors, 15 were in contact with animals, which showed 7 people had positive Toxoplasma antibodies, confirming that animals are a significant risk factor of infection. 
Table 5 The relation between seropositivity and donor's blood group.

\begin{tabular}{|l|l|l|l|l|}
\hline \multicolumn{2}{|l|}{ Blood groups } & Results & \multirow{2}{*}{ Total } \\
\cline { 3 - 5 } \multicolumn{2}{|c|}{} & Seropositive & Seronegative & \\
\hline \multirow{2}{*}{ A- } & Count & 9 & 4 & 13 \\
\cline { 2 - 5 } & $\%$ of Total & 5.5 & 2.4 & 7.9 \\
\hline \multirow{3}{*}{ A+ } & Count & 11 & 22 & 33 \\
\cline { 2 - 5 } & $\%$ of Total & 6.7 & 13.4 & 20.1 \\
\hline \multirow{3}{*}{ AB- } & Count & 0 & 1 & 1 \\
\cline { 2 - 5 } & $\%$ of Total & 0.0 & 0.6 & 0.6 \\
\hline \multirow{3}{*}{ AB+ } & Count & 3 & 3 & 6 \\
\cline { 2 - 5 } & $\%$ of Total & 1.8 & 1.8 & 3.7 \\
\hline \multirow{3}{*}{ B- } & Count & 2 & 2 & 4 \\
\cline { 2 - 5 } & $\%$ of Total & 1.2 & 1.2 & 2.4 \\
\hline \multirow{3}{*}{ B+ } & Count & 11 & 23 & 34 \\
\cline { 2 - 5 } & $\%$ of Total & 6.7 & 14.0 & 20.7 \\
\hline \multirow{2}{*}{ O- } & Count & 19 & 54 & 73 \\
\cline { 2 - 5 } & $\%$ of Total & 11.6 & 32.9 & 44.5 \\
\hline \multirow{2}{*}{ Total } & Count & 55 & 109 & 164 \\
\cline { 2 - 5 } & $\%$ of Total & 33.5 & 66.5 & 100.0 \\
\hline
\end{tabular}

Data represented different blood groups. Results showed significant $(\mathrm{P}<0.05)$ effect between blood group and seropositive. This effect could be due to different sample size variation collected from different places.

Table 6 The relation between seropositivity and blood transfusion.

\begin{tabular}{|l|l|l|l|l|}
\hline \multicolumn{2}{|l|}{ Blood transfusion } & \multicolumn{2}{|l|}{ Results } & \multirow{2}{*}{ Total } \\
\cline { 3 - 4 } \multicolumn{2}{|l}{} & Seropositive & Seronegative & \\
\hline \multirow{3}{*}{ Yes } & Count & 4 & 3 & 7 \\
\cline { 2 - 5 } & $\%$ of Total & 2.4 & 1.8 & 4.3 \\
\hline \multirow{2}{*}{ No } & Count & 51 & 106 & 157 \\
\cline { 2 - 5 } & $\%$ of Total & 31.1 & 64.6 & 95.7 \\
\hline \multirow{2}{*}{ Total } & Count & 55 & 109 & 164 \\
\cline { 2 - 5 } & $\%$ of Total & 33.5 & 66.5 & 100.0 \\
\hline
\end{tabular}

Data showed that only 7 individuals received a blood transfusion in the past. As a result, we found that 4 cases tested positive for Toxoplasma antibodies. Therefore, suggested potential care should be considered, including screening for Toxoplasma antibodies in blood donors.

\section{Discussion}

Identification of T. gondii could be by serologic tests or PCR (Polymerase chain reaction through amplification of specific nucleic acid sequences). After infection, IgM antibodies may appear in the blood earlier and disappear rapidly. However, 
IgG can also appear early and could persist for life (10). Therefore, a selection of a specific method for the diagnosis of Toxoplasma gondii antibodies is recommended. Different medical methods are sometimes needed to determine whether or not a patient has been presumably infected within the distant past or has been recently infected. The practitioner and clinical laboratories should be aware of these issues and consult reference laboratories if the requirement arises. Infection by Toxoplasma gondii during pregnancy could lead to severe complications either for the fetus or infants, while in the immunocompromised, severe complications could have resulted. Moreover, some studies showed positive results of Toxoplasma antibodies in individual blood donor's individual, which was the main target in this study. Therefore, our main objective in this study is to search for the prevalence of Toxoplasma antibodies in blood donors. Our study showed that out of a total of 15 blood donors who lived or were in contacted with animals (46.6\%) had seropositivity of Toxoplasma gondii antibodies, and the remaining (53.4\%) had not. As a result, there was no statistical association. A similar study conducted in Benghazi reported that $47.7 \%$ of pregnant women tested positive for the Toxoplasma antibody whereas, in Tripoli, the prevalence was reported as 38.5\% (11). In Libya also, abortions in 38.5\% of women were found to be seropositive; 36 (66.6\%) were positive IgG antibodies, 12 (22.2\%) had both IgG and IgM antibodies, whereas $6(11.1 \%)$ for IgM. Moreover, recurrent abortion was found in women who had IgG-positive (4). In the current study, $33.5 \%$ of blood donors had positive antibodies in their serum. In contrast, In Nigeria, the prevalence of T. gondii was found in 49 (19.8\%) out of 249 blood donors. However, the majority (58\%) was in the age group of 29-39 years old (12), which is similar to our study in which the majority of infected individuals were in the age group of 25 - 31 years old. This is because blood donors in this age group prefer to eat fast food and barbeque meat, which may be contaminated with oocysts of $T$. gondii. Another important finding in our study higher prevalence of Toxoplasma antibodies in unemployed people with low education rather than the engineers or students groups,17.1\% vs. $0 \%$ and $2.4 \%$ respectively, which confirmed education is an important factor in reducing the spread of the infection. This study showed that more than $4 \%$ of the healthy blood donors in the Tripoli area were in contact with animals that tested positive for Toxoplasma antibodies, and $2.4 \%$ that received a blood transfusion tested positive. This confirmed that both infected animal contact and blood transfusion are associated with Toxoplasma gondii transmission. In Egypt, 155 out of 260(59.6\%) blood donors screened for T.gondii antibodies in Mansoura University hospital showed seropositive for IgG; however, in our study 55 (33.5\%) out of a total of 164 subjects were had positive antibodies (13). In India, the prevalence of IgG and IgM antibodies was 51.8\% and 5\% respectively (14).

\section{Conclusion}

T. gondii antibodies' prevalence was observed in people of low education and in people who consume undercooked meat, vegetables, or fruit. This study highlights that T. gondii is prevalent among healthy blood donors in Tripoli health centers. Toxoplasmosis can cause serious complications, especially to those with an immunocompromised system. Therefore, there is a need for T. gondii screening tests to be involved in the blood donation scheme to ensure safe blood transfusion.

\section{Compliance with ethical standards}

\section{Acknowledgments}

We want to thank all those who helped us to gives us the chance to collect our data from Algala, Abusalim Tripoli hospital. We would also like to express our thanks to Ahmad Elhadi and Ali altorkei for their support. Special thanks to the staff of the Libyan National center for infectious disease for their support.

\section{Disclosure of conflict of interest}

The authors declare no conflict of interest.

\section{Statement of informed consent}

Patients in this study gave their informed consent.

\section{References}

[1] Al-Adhroey A, Mehrass A, Al-Shammakh A, Ali A, Akabat M, Al-Mekhlafi H. Prevalence, and predictors of Toxoplasma gondii infection in pregnant women from Dhamar, Yemen. BMC Infect Dis. 2019; (19): 1089.

[2] Weissa L, Dubey J. Toxoplasmosis: a history of clinical observations. Int J Parasitol. 2009; 39(8): 895-901. 
[3] Márcia Attias, Dirceu E. Teixeira, Marlene Benchimol, Rossiane C. Vommaro, Crepaldi P, De Souza W. The life cycle of Toxoplasma gondii reviewed using animations. Parasites \& Vectors. 2020; (13): 588.

[4] Siransy L, Dasse S, Dou Gonat S, Legbedji A, Guessan K, Kouacou P, Yeboah R, Menan H. Immunity Status of Blood Donors Regarding Toxoplasma gondii Infection in a Low-Income District of Abidjan. West Africa Journal of Immunology Research. 2016; 8

[5] Saadatnia G, Golkar M. A review on human toxoplasmosis. Scandinavian Journal of Infectious Diseases. 2012; (44): 805-814.

[6] Mohamed k. Review Toxoplasmosis in humans and animals in Saudi Arabia: A systematic review. J Infect Dev Ctries. 2020; 14(8): 800-811.

[7] Amoo A, Njaanake K, Adegbola H, Manyonyi G. Toxoplasmosis among blood donors: Unsafe blood transfusion in ibadan, southwest Nigeria. Journal of applied Haematology. 2019; 10 (4): 120-125.

[8] Abdulelah H. Al-Adhroey, Amat Al-Khaleq O. Mehrass, Abdulqawi A. Al-Shammakh, Abdullatif D. Ali, Mohammed YM Akabat, Hesham M. Al-Mekhlafi. Prevalence and predictors of Toxoplasma gondii infection in pregnant women from Dhamar, Yemen. BMC Infect Dis. 2019; 19: 1089.

[9] Rad M, Majidiani H , Dalvand S, Daryani A, Kooti W, Saki J , -Rad F, Ehsan Ahmadpour. Toxoplasmosis in Blood Donors: A Systematic Review and Meta-Analysis. Tranfus Med Rev. 2016; 30 (3): 116-22.

[10] Montoya JG. Laboratory Diagnosis of Toxoplasma gondii Infection and Toxoplasmosis. The Journal of Infectious Diseases. 2002; 1(185): 73-82.

[11] Rouatbi M, Amairia S, Amdouni Y, Boussaadoun M, Ayadi O, Al-Hosary A, Rekik M, Abdallah R, Aoun K, Darghouth M, Wieland B, Gharbi M. Toxoplasma gondii infection and toxoplasmosis in North Africa: a review. Parasite. 2019; 26: 6.

[12] Majidiani R, Dalvand S, Daryani A, Kooti W, Saki J, Hedayati R, Ahmadpour E. Toxoplasmosis in Blood Donors: A Systematic Review and Meta-Analysis. Transfus Med Rev. 2016; 30(3): 116-22.

[13] Elsheikha H, Azab M, Abousamra N, Rahbar M, Elghannam D, Raafat D. Seroprevalence of and risk factors for Toxoplasma gondii antibodies among asymptomatic blood donors in Egypt. Parasitol Res. 2009; 104(6): 14711614.

[14] Edwards B, Vayalumkal, Chawla R, Fonseca K, Hong Zhou. Asymmetric eye size in an infant. Official Journal of the Association of Medical Microbiology and Infectious Disease Canada. 2020; 5(3): 129-136. 